\title{
Modeling enterprise location choice decision behavior
}

\author{
Nguyen Cao Y \\ University of Transport and Communications \\ ynguyencao82@utc.edu.vn
}

\begin{abstract}
This study presents a location choice model that incorporates urban spatial effects for enterprises. A modeling framework is developed to analyze decisions regarding location choice for enterprises using a series of discrete choice models including multinomial logit without any urban spatial effects, multinomial logit incorporating urban spatial effects, and mixed logit incorporating urban spatial effects. In this framework, urban spatial effects, such as the urban spatial correlation among enterprises in deterministic terms and the urban spatial correlation among zones in the error term, are captured by mixed logit models in particular and discrete choice models in general.

The results indicate that the urban spatial effects and the land prices in a given zone strongly affect the decision-making process of all the enterprises in the Tokyo metropolitan area. Moreover, the important role of urban spatial effects in the proposed model will be clarification through comparing the three above models. This comparison will be implemented on the basis of three types of indicators such as the log likelihood ratio, Akaike information indicator, and hit ratio of each model.
\end{abstract}

Keywords: Mixed logit, location decision behavior, location choice model

\section{Article history:}

Received: February 22, 2020

Received in revised form:

December 1, 2020

Accepted: April 23, 2021

Available online: June 22, 2021

\section{Introduction}

The primary motives of a location choice decision are caused by the characteristics of enterprises, zone's attributes, interactions among enterprises and zone alternatives in terms of urban spatial effects. Regional planners, therefore, need a proper location choice model in order to determine the most effective mechanisms to attract businesses, and thereby maintain a healthy economy. The microscopic modeling approach, which is currently gaining more favor in linking transport and land use planning of both residents and enterprises, is found to be suitable for modeling location choice since it can reflect the real mechanism of the choice behavior of each enterprise (Wisetjindawat, Sano, \& Matsumoto, 2006). This paper's aim is to develop a model that considers the influence of observable and unobservable factors on the location choice decision of each enterprise and its interaction within dynamic business environments.

Copyright 2021 Nguyen Cao Y

http://dx.doi.org/10.5198/jtlu.2021.1743

ISSN: 1938-7849 | Licensed under the Creative Commons Attribution - Noncommercial License 4.0

The Journal of Transport and Land Use is the official journal of the World Society for Transport and Land Use (WSTLUR) and is published and sponsored by the University of Minnesota Center for Transportation Studies. 
The individual enterprise location choice decision process incorporating urban spatial effects is illustrated in the model conceptual framework. In which, a series of discrete choice models have been applied to explain these processes when considering the urban spatial effects in the business dynamic environment. In addition, the maximum likelihood estimation has been used to estimate the parameters of each proposed model.

The rest of this paper is organized as follows. The next section introduces the literature review of the application of discrete choice models and provides a basis for discrete choice models with structuralized urban spatial effects. The third section describes the approach taken in this study, which uses a mixed logit model framework for location choice behavior in which the error term reflects the urban spatial correlation among zones and the deterministic term reflects the correlation among enterprises, given the fraction of consumption between enterprise and suppliers. The fourth section presents a case study based on data from the Tokyo Metropolitan area. Discussion of the results, the conclusions and recommendations are presented in the fifth section and the sixth section, respectively.

\section{$2 \quad$ Literature review}

From the 1980s onwards, there has been a renewed interest in urban economic perspectives such as urban economic geography generally and urban economic agglomeration particularly. Fotheringham (1983) pointed out that new interaction models were termed competing destinations models, and estimated distance-decay parameters obtained in his calibration are shown to have a purely behavioural interpretation. Pellegrini and Fotheringham (2002) drew upon empirical application of spatial choice models to interregional migration and identifies the main research issues, summarizes the progress of research thus far, and suggests some paths for future research. They suggest that analysts engaged in interregional migration modeling risk model misspecification if the peculiarities of spatial choice are ignored. Maoh and Kanaroglou (2007) presented a micro analytical firm mobility model for the City of Hamilton, Canada, developed with data from the Statistics Canada Business Register. In this article evidence is provided that the willingness to move can be explained by firm's internal characteristics (e.g. age, size, growth and industry type) as well as location factors related to the urban environment where the firm is located. De Bok and van Oort (2011) presented a firm location study in which the different types of spatial externalities in the urban context were addressed. They confirm that firm relocation behavior is affected much more by firm-level attributes (size, age, and growth rate) than by agglomeration and accessibility attributes.

Numerous studies have examined the relative significance of various factors in the business location choice process by developing theoretical models to explain the different facets of the process (OzmenErtekin, Ozbay, \& Holguín-Veras, 2007). In practice, the choice of location is determined by an individual firm, which follows a complex process to evaluate the trade-offs among different locations. The choice of location is generally influenced by factors such as the characteristics of the firm, the attributes of the zones being considered, and transportation accessibility (Ozmen-Ertekin et al., 2007). Moreover, the interplay among individual firms can be viewed as interactions in a space. In urban economics, related firms that gather together will gain benefits such as lower cost of production and a greater market share that one firm can achieve. A firm, while making location choice decisions, does not act in isolation; in contrast, firms are influenced by others who are located nearby (Wisetjindawat et al., 2006).

In the long history of the application of discrete choice models, enormous progress has been made in the field of disaggregate choice modeling with spatial effects. Boots and Kanaroglou (1988) incorporated the effect of spatial structure in discrete choice models of migration. Dubin (1995) developed a spatial binary logit model to predict the diffusion of a technological innovation. In Dubin's model, 
the probability of the adoption of a new technology varies depending upon an enterprise's own characteristics and its interactions with those who have previously adopted its technology. Paez and Suzuki (2001) tested the application of a spatial binary logit model to a land-use problem related to the effects of transportation on changes in land use. Mohammadian and Kanaroglou (2003) expanded the binary choice model into a more general form to derive a spatial multinomial logit model and tested it on a problem related to the choice of housing type. Löchl and Axhausen (2010) applied the UrbanSim software to modeling hedonic residential rents for land use and transport simulation while considering spatial effects. Spatial simultaneous autoregressive approaches proved to be a reasonable alternative in the analysis, which can be implemented in UrbanSim more easily because of its structure of a single set of resulting parameters in his research. Schirmer, van Eggermond, \& Axhausen (2014) not only considered the role of location in residential location choice models but also proposed a common classification for location variables and categorize findings from a wide range. His results showed that in addition points of interest (e.g., schools, school quality, retail, transport elements) and previous residential locations are attributes that should be included in choice models in transport land-use simulations. Van Dijk and Pellenbarg (2017) pointed out that the spatial scale is important in firm migration, because the causes and the effects differ substantially for firm relocations within urban areas and between regions within countries, and for international relocations between countries or even continents. Nilsen, Tørset, Gutiérrez, Cherchi, \& Andersen (2020) indicated that the relocate decision which is influenced by a firm's internal and external characteristics such as agglomerations.

Bhat and Guo (2004) proposed a mixed spatially correlated logit (MSCL) model for location- related choices. The MSCL model is a powerful approach that can capture both random variations in taste and spatial correlation in location choice analysis. The empirical results underscore the need to account for these variations and this spatial correlation, both to obtain an improved data fit and to realistically assess the effect of socio-demographic, transportation system, and land use changes on residential location choices. In addition, Miyamoto, Vichiensan, Shimomura, and Paez (2004) presented a discrete choice model with a systematic specification of the spatial influences upon the choice process. The utility function of this model is specified with autoregressive expressions for the deterministic and error component, and the model is evaluated with reference to three alternative models: the standard logit model, a logit model with an autoregressive deterministic term, and a mixed logit model with autoregressive error terms. Furthermore, Mohammadian, Haider, and Kanaroglou (2005) attempted to incorporate spatial dependencies in random parameter discrete choice models. They formulated a mixed spatial multinomial logit model that incorporates spatial dependencies to predict the choice of type for new housing projects. They formulated a mixed spatial multinomial logit model that incorporates spatial dependencies to predict the choice of type for new housing projects. Their results suggested that the housing project's choices were influenced by factors related to other projects in adjacent zones, resulting in correlated choice behavior over space.

This study may distinguish from above studies in several respects. First, this research considers the urban spatial correlation not only in the deterministic part but also in the random part of the utility function of a company location choice decision behavior, while most previous research focuses on residential location choice decision. Second, this study proposed a company location choice by using a mixed logit model to represent the urban spatial autocorrelation on realistic location choice behavior while the previous studies used a multinomial logit model or nested logit model for an enterprise location choice model, which is unable to accommodate urban spatial autocorrelation in the random part of the utility function. Finally, this paper considers a reasonably comprehensive set of determinants of an enterprise location choice, on the basis of the empirical findings from the previous research. 


\section{Methodology}

\subsection{Conceptual framework of location choice models}

In the scope of this proposed model, the spatial dimensions of business location decisions are the distribution of establishments that are the result of start-ups location decisions and past relocation decisions.

Location is a term defining the places where land use activities are established in space in the urban context (Maoh et al., 2007). The determinants of business location are multifaceted, complex and interactive. However, it is necessary to provide a framework in which these can be classified. Within a national context, businesses will locate where they have better access to markets and factors of production. Access to markets and inputs (including employees, links to suppliers, knowledge of and access to production and product technology changes, market knowledge), and their availability, quality and costs, will be influenced by transport infrastructure (McQuaid, Greig, Smyth, \& Cooper, 2004). In general, all approaches of the empirical research have in common that they represent the firm as an active decision-making agent: a firm chooses a location from a number of alternatives. By doing so, it takes economic and or non-economic factors into account (de Bok \& Sanders, 2005).

Firm relocation is a particular form of location adjustment of the firm. Pellenbarg, van Wissen, and van Dijk (2002) defines firm relocation as a change of address of a firm from location A to location B. This definition is most suited for small and medium sized single plant firms, but less for multi plant firms and large enterprises. With regard to the aspect of spatial moves, Pellenbarg et al. (2002) proposes the definition of firm relocation into at least three categories, namely intra-regional, inter-regional, and international level

The paper proposes the realistic location choice model to analyze decisions regarding location choice for enterprises using a series of discrete choice model including multinomial logit without any urban spatial effects, multinomial logit incorporating urban spatial effects and mixed logit incorporating urban spatial effects. In which, mixed logit model accommodating urban spatial effects in both parts which includes the deterministic parts and random parts of utility functions to represent the urban spatial correlation among enterprises and the urban spatial correlation among zones in the enterprise location choice behavior.

\subsection{Mixed logit model framework for behavior when making location choice decisions}

\subsubsection{Mixed logit models for location choice decision behavior}

A mixed logit model, which consists of a flexible probit-like term and an additive iid extreme value term, is utilized to explain the choice decision process and incorporates the spatial interaction in the disturbance term. According to the work of Ben-Akiva, Bolduc, and Walker (2001), the vector of the utility of alternatives for individual enterprise takes the general form of the mixed logit model as follows:

$\mathrm{U}_{\mathrm{ni}}=\sum_{k=1}^{K} \beta_{k} X_{n i k}+F_{n i} T \zeta_{n i}+v_{n i}$

The deterministic part of the utility function is represented by the first term $\beta_{k} X_{n i k}$, where $\beta_{k}$ is the $[\mathrm{K} \times 1]$ vector of unknown parameters and $X_{\text {nik }}$ is the $[\mathrm{Z} \times \mathrm{K}]$ matrix of explanatory variables for each 
individual enterprise $\mathrm{n}$. The disturbance term is depicted by the second and third terms $F_{n i} T \zeta_{n i}$ and $v_{n i} . F_{n i} T \zeta_{n i}$ represents the covariance structure among alternative zones, where $F_{n i}$ is the $[\mathrm{Z} \times \mathrm{Z}]$ matrix of factor loading that is used to construct the pattern of correlation, $T$ is the $[Z \times Z]$ matrix of standard deviation with $\sigma$ on the diagonal, and $\zeta_{n i}$ is the $[Z \times 1]$ vector of random numbers with zero mean and unit variance; in this study, we assume $\mathrm{N}(0,1) . v_{n i}$ is the $[Z \times 1]$ vector of $i i d$ gumbel random variables.

The probability of the alternative i being selected by an individual enterprise $n$ is the integral of standard logit probabilities over a density of parameters. The conditional probability that zone $\mathrm{i}$ is chosen by an individual enterprise $\mathrm{n}$ is formulated as follows:

$$
\begin{aligned}
P_{n i} & =\int \Lambda\left(\frac{i}{\zeta}\right) n\left(\zeta, I_{Z}\right) d \zeta \\
P_{n i} & =\int\left(\frac{\exp \left(\sum_{k=1}^{K} \beta_{k} X_{n i k}+F_{n i} T \zeta_{n i}\right.}{\sum_{i^{\prime}=1}^{\mathrm{Z}} \exp \left(\sum_{k=1}^{K} \beta_{k} X_{n i^{\prime} k}+F_{n i^{\prime}} T \zeta_{n i^{\prime}}\right.}\right) n\left(\zeta, I_{Z}\right) d \zeta
\end{aligned}
$$

Where $X_{n i k}$ is $i^{\text {th }}$ row of matrix $X_{n}$ representing attributes of zones for an enterprise $\mathrm{n} ; \beta_{k}$ is the matrix of parameters to be calibrated, $F_{n i} T \zeta_{n i}$ is the covariance structure for an individual enterprise $\mathrm{n}, F_{n i}$ is the $i^{\text {th }}$ row of the matrix in $F_{n i}, i^{\prime}$ is a zone in $Z$, which is a set of all alternative zones, $\Lambda\left(\frac{i}{\zeta}\right)$ is the logit part of the model, and is the probability that the choice is i given $\zeta, n\left(\zeta, I_{Z}\right)$ is the joint density function of $\zeta$, and is a product of the standard univariate normal.

$$
n\left(\zeta, I_{Z}\right)=\prod_{i=1}^{Z} \phi\left(\zeta_{i}\right)
$$

\subsubsection{Urban spatial correlation among enterprises in deterministic term}

The deterministic term of the utility function is written in the general way when incorporating urban spatial effects or in the autoregressive form as follows:

$$
\mathrm{V}_{\mathrm{ni}}=\lambda W V_{n i}+\sum_{k=1}^{K} \beta_{k} X_{n i k}
$$

Where $V_{n i}$ is the deterministic part of the utility function, $\lambda$ is the parameter indicating the urban spatial interactions, $\mathrm{W}$ is the urban spatial weight matrix, $\beta_{k}$ is the unknown parameters, $X_{\text {nik }}$ is the characteristics of alternative $\mathrm{i}$; decision maker $\mathrm{n}$.

In this manner, with the i.i.d errors, we obtain a so-called logit model with the autoregressive deterministic term (Ben-Akiva et al., 2001). The researcher may also specify the urban spatial dependence in the deterministic term differently such as directly specifying the correlation function, which results in the deterministic term as follows:

$$
\mathrm{V}_{\mathrm{ni}}=\alpha f\left(d_{n s}\right)+\sum_{k=1}^{K} \beta_{k} X_{n i k}
$$


Where $f\left(d_{n s}\right)$ is the correlation vector as a function of distances between enterprise $\mathrm{n}$ and $\mathrm{s}, \alpha$ is an unknown parameter.

After adding the interactions, the systematic utility function of alternative $i$ for enterprise $\mathrm{n}$ is given as follows:

$$
\left.\mathrm{U}_{\mathrm{ni}}=\sum_{k=1}^{K} \beta_{k} X_{n i k}+\sum_{s=1}^{S}\left(\lambda \exp \left(-d_{n s i}^{\delta}\right) y_{s i}\right)+\varepsilon_{n i}\right)
$$

Where $\beta_{k}$ is the parameter which make up a vector of parameters (to be estimated); $\lambda, \delta$ are the parameters to be estimated, $X_{\text {nik }}$ is the vector of observed characteristics of an alternative $i$, and an individual enterprise $n, y_{s i}$ is set equal to unity if the individual enterprise $s$ has chosen alternative $\mathrm{i}$, and zero otherwise, $S$ is the number of individual enterprises who have influence on $n, d_{n s}$ is the distance between an individual enterprise $n$ and an individual enterprise $s$ which come from one industry.

\subsubsection{Urban spatial correlation among zones in the error term}

The spatial autoregressive term inserted into the disturbance term of the probit model has been successfully applied to housing choice behavior in the model of McMillen (1992). Moreover, Ben-Akiva et al. (2001) suggested the addition of a generalized autoregressive term to the disturbance term of mixed logit. This study, therefore, utilizes the generalized autoregressive term to explain the urban spatial correlation among zones.

$$
\begin{gathered}
\varepsilon_{n i}=\varphi_{i j} \varepsilon_{n i}+T \zeta_{n i} \\
\varphi_{i j}=\rho W \\
\varepsilon_{n i}=\rho W \varepsilon_{n i}+T \zeta_{n i} \\
\varepsilon_{n i}=(I-\rho W)^{-1} T \zeta_{n i} \\
\varepsilon_{n i}=F_{n i} T \zeta_{n i}
\end{gathered}
$$

Where $\varphi_{i j}$ is the urban spatial correlation between zone $\mathrm{i}$ and zone $\mathrm{j}, \varepsilon_{n i}$ is the disturbance term of mixed logit, $\rho$ is the scalar unknown parameter, $\mathrm{I}$ is the $[\mathrm{Z} \times \mathrm{Z}]$ identity matrix, $\mathrm{W}$ is the $[\mathrm{Z} \times \mathrm{Z}]$ weight matrix identifying the urban spatial correlation among zones, $F_{n i}$ is the loading factor, which assumes the same for the enterprises, $\zeta_{n i}$ is the $[\mathrm{M} \times 1]$ vector of the random numbers with zero mean and unit variance, which can be assumed to any types of distribution.

Because $\zeta_{n i}$ is a vector of random numbers with zero mean and unit variance, it can be assumed normal random distribution and generated easily by Gauss program in this study. 
$T=\sigma I$

Where $\mathrm{T}$ is the lower triangular matrix of unknown parameter $\sigma ; \sigma$ is the scalar representing standard deviation, $I$ is the identity matrix.

$$
\Lambda\left(\frac{i}{\zeta_{n i}}\right)=\frac{\exp \left(\sum_{k=1}^{K} \beta_{k} X_{n i k}+(I-\rho W)_{i}^{-1} T \zeta_{n i}\right)}{\sum_{\mathrm{i}^{\prime}=1}^{\mathrm{Z}} \exp \left(\sum_{k=1}^{K} \beta_{k} X_{n i^{\prime} k}+(I-\rho W)_{i}^{-1} T \zeta_{n i^{\prime}}\right)}
$$

Where $(I-\rho W)_{i}^{-1}$ is $i^{\text {th }}$ row of the matrix $(I-\rho W)^{-1}$

\section{Urban spatial weights matrix using for correlation among zones}

Specification of urban spatial weights matrix is a critical task in developing urban spatial models. It requires a good understanding of both the spatial statistics and the subject process under the study. Popular functions used in the weights matrix in the literature include adjacency indices and those distancesbased functions (Griffith, 1996).

First, many distance-based weighting functions have been proposed for use in the weights matrix. It is always assumed that the distance from site $i$ to $\operatorname{site} j, d_{i j}$ is the same as the distance from site $j$ to site $i, d_{i j}$ ( Miaou \& Sui, 2004). Inverse distance weighting function with a fixed parameter $\gamma=2$.

$$
w_{i j}=\frac{1}{d_{i j}^{\gamma}}=\frac{1}{d_{i j}^{2}}
$$

Where, $w_{i j}$ is the element of weight matrix $W, d_{i j}$ is the distance between zones $i$ and $j$.

The second way is to determine the spatial weight matrix. Bhat and Guo (2004) propose the adjacency weight matrix that is used to measure the level of correlation between zones. An adjacency matrix is defined as a symmetric with zero diagonal elements and off-diagonal elements equal to 1 if site is a neighbor to the other site and 0 otherwise. Therefore, this research utilizes the method of adjacency weight matrix for estimating the weight matrix among zones. The formula of the adjacency weight matrix (W) which is proposed by Bhat and Guo (2004) can be expressed as follows:

$w_{i j}=\frac{\omega_{i j}}{\sum_{k} \omega_{i k}}$

Where $w_{i j}$ is the off-diagonal element of adjacency weight matrix $(\mathrm{W}), \omega_{i j}=1$ if zone $\mathrm{j}$ shares a common boundary with zone $\mathrm{i}$ and 0 otherwise. 


\subsection{Simulation}

Mixed logit is well suited to simulation methods for estimation (Train, 2003). The utility function can be expressed as follows:

$$
U_{n i}=X_{n i} \beta_{n}+\varepsilon_{n i}
$$

Where $\beta_{n}$ is distributed with density $f(\underset{\theta}{\beta}), \theta$ refers collectively to the parameters of this distribution (such as the mean and covariance of $\beta_{n}$ ).

The researcher specifies the function form $f($.) and wants to estimate the parameters $\theta$ (Train, 2003). The choice probabilities are:

$P_{n i}(\theta)=\int L_{n i}(\beta) f\left(\frac{\beta}{\theta}\right) d(\beta)$

Where,

$L_{n i}\left(\beta_{n}\right)=\frac{\exp \left(X_{n i} \beta_{n}\right)}{\sum_{j=1}^{J_{n}} \exp \left(X_{n j} \beta_{n}\right)}$

The probabilities are approximated through the simulator for any given value of $\theta$ : (1) Draw a value of $\beta_{n}$ from $f\left(\frac{\beta}{\theta}\right)$, and label it $\beta_{n}{ }^{r}$ with the superscript $\mathrm{r}=1$ referring to the first draw; (2) Calculate the logit formula $L_{n i}\left(\beta_{n}^{r}\right)$ with this draw; (3) Repeat steps 1 and 2 many times, and average the results. The average value of these probabilities yields the following simulated probability:

$\widehat{\mathrm{P}}_{n i}(\theta)=\frac{1}{R} \sum_{r=1}^{R} L_{n i}\left(\beta^{r}\right)$

Where $\mathrm{R}$ is the total number of draws, $\hat{P}_{n i}$ is the unbiased estimator of $P_{n i}$ by construction.

This simulated probability is an unbiased estimator whose variance decreases as the number of draws $\mathrm{R}$ increases. It is strictly positive so that $\ln \left(\hat{P}_{n i}\right)$ is defined, which is useful for approximating the $\log$-likelihood function below. $\hat{P}_{n i}$ is smooth (twice differentiable) in the parameters $\theta$ and in the variables $X$, which facilitates numerical research for the maximum likelihood function and the calculation of elasticity (Train, 2003). The simulated probabilities of a model that incorporates spatial correlation among firms in the deterministic term, and incorporates the spatial correlation among zones in the error term as follows: 


$$
\widehat{\mathrm{P}}_{n i}=\frac{1}{R} \sum_{r=1}^{R} \frac{\exp \left(\sum_{k=1}^{K} \beta_{k} X_{n i k}+\sum_{s=1}^{S}\left(\lambda \exp \left(-d_{n s i}^{\delta}\right) y_{s i}\right)+(I-\rho W)_{i}^{-1} T \zeta_{n i}\right)}{\sum_{j=1}^{J} \exp \left(\sum_{k=1}^{K} \beta_{k} X_{n j k}+\sum_{s=1}^{S}\left(\lambda \exp \left(-d_{n s j}^{\delta}\right) y_{s j}\right)+(I-\rho W)_{j}^{-1} T \zeta_{n j}\right)}
$$

Where $\mathrm{R}$ is the total number of draws, $X_{\text {nik }}$ is the $\left(J_{n} \times K\right)$ matrix of explanatory variables, $\beta_{k}$ is the $(\mathrm{K} \times 1)$ vector of unknown parameters, $\lambda, \delta$ are the unknown parameters, $\rho$ is the parameter indicating the spatial autocorrelation, $\mathrm{W}$ is the spatial weight matrix, $\mathrm{I}$ is the identity matrix, $\mathrm{T}$ is the lower triangular matrix of unknown parameter $\sigma, \zeta_{n i}$ is the vector of i.i.d random variables with zero mean and unit variance.

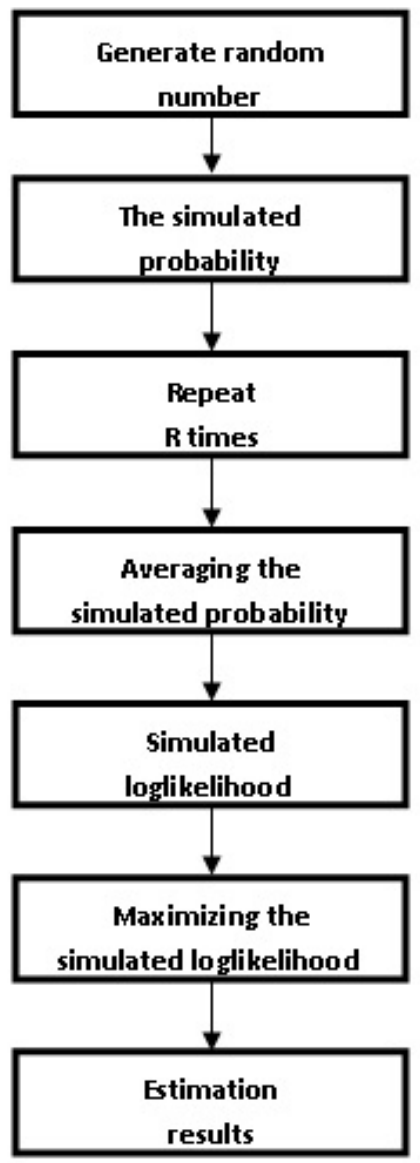

Figure 1. Maximum likelihood estimation process

The parameters can be estimated by the maximum likelihood method. Because the true log likelihood cannot be calculated, the simulated maximum likelihood technique is used with the following formula:

$$
\operatorname{SML}(\theta)=\sum_{n=1}^{N}\left(\sum_{i=1}^{Z} y_{n i} \log \widehat{P}_{n i}(\theta)\right)
$$


Where $y_{n i}$ will be set equal to unity if the individual firm $n$ has chosen alternative $i$, and zero otherwise, $\mathrm{N}$ is the total number of individual firms, $\mathrm{Z}$ is the total number of alternatives or zones;

The GAUSS programming language is utilized to make the program of the proposed models. Bhat's Gauss code for a scrambled Halton sequence is modified and integrated into our maximum simulated likelihood estimation code (Bhat, 2003).

\section{$4 \quad$ Data collection for case study}

The study area is the Tokyo metropolitan area which consists of the city of Tokyo, Kanazawa prefecture, Saitama prefecture, Chiba prefecture and South Ibaraki prefecture.

The attributes of each zone, the characteristics of each individual firm and spatial interactions have been collected from numerous data source. In which, the population of the zone was collected from the Population census of Japan. The number of employees of the zone were collected from the Establishment and Enterprise Census. Furthermore, the average land price of zones were collected from the Land Price Survey of Japan. The characteristics of each individual firm were collected from the TMGMS. The address of each individual firm is available in the TMGMS. Therefore, the distance among the firms can be calculated directly from the address of each firm. However, to simply make the computation, the distance among the firms can be calculated on basis of the distance among $\mathrm{C}$ zone types (based on the three-digit city code) which each individual firm belongs to. Finally, the spatial weight matrix of zones is computed on basis of the average traveling distance among zones. The total number of zones is 52 zones based on the two digits of city code in the Tokyo metropolitan area. The distance among 52 zones has been utilized in this study based on the data of Road traffic census.

The Tokyo metropolitan area can be divided into some zone levels such as A zone level, B zone level, C zone level. Regard to the A,B,C zone level, The Tokyo metropolitan area is composed of 17, 56, 335 zones with zone code, respectively. The purpose of the study focuses on the enterprise location choice decision. However, in the scope of this research, B zone type is chosen to consider the enterprise location choice model. The reason for this is that the origin data can be collected from B zone type, because most main surveys focus on B zone types. The main surveys are the Tokyo Metropolitan Good Movement Survey, Establishment and Enterprise Census and Road Traffic Census. Regard to the B zone level, the Tokyo metropolitan area is composed of 56 zones with zone code. However, there are five zones such as zone 15 , zone 16 , zone 17 , zone 18 and zone 19 which are not available in the study area. Therefore, the total number of zones is 52 zones in the study area. Figure 2 illustrates the B zoning system and the scope of the study area. 


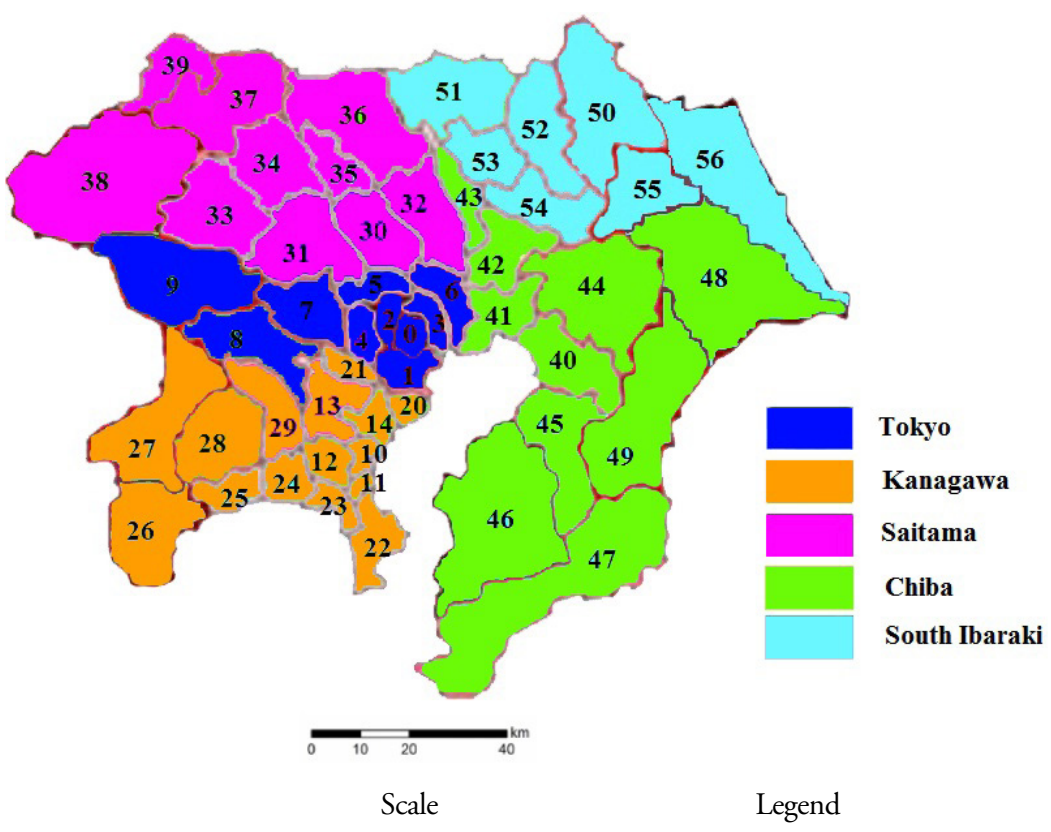

Figure 2. Tokyo metropolitan area

The Figure 3 shows the enterprise distribution based on the distance from enterprise location to the nearest IC highway for eight industry types. It's straightforward to see that most enterprises of all types of industries locations are near the IC highway. Product wholesalers and material wholesalers have the highest number of the enterprises which located in the radius of $2 \mathrm{~km}$ to the IC highway. However, this number decreases sharply when the radius to the IC highway increases to $4 \mathrm{~km}$ or $6 \mathrm{~km}$. Other manufacturers also have the same tendency to that of the wholesalers. Even though, the enterprise number of all industries have a decreasing tendency when the radius to the nearest IC highway increases, the variation of this tendency is different among industries. The number of retailers and machinery manufacturers are lowest in the radius of $2 \mathrm{~km}$. However, these numbers increase in a radius of $4 \mathrm{~km}$. This means that retailers and machinery manufacturers are often located to the nearest IC highway father than that of other industries.

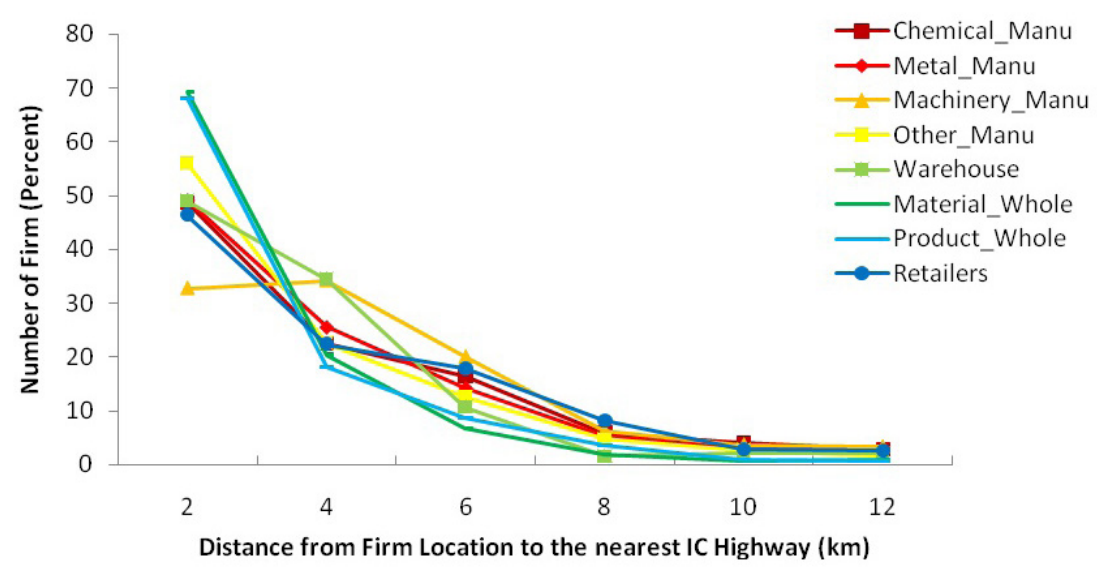

Figure 3. The enterprise distribution based on the distance 
Figure 4 illustrates the enterprise distribution based on the land price of enterprise location for eight industry types. Figure 4 shows that there are a large number of enterprises of each kind of industry located in locations with low land prices. The number of enterprises decreases slightly when the land price of location increases for each kind of industry. It can be explained that there are many enterprises which choose locations with higher land prices if those locations have other benefits for them. However, the tendency of a number of enterprises will decrease when the land price of location increases. Therefore, the land price of location should be considered in the location choice model with the other factors to make more clearly the influence of the land price on enterprise location choice decision. In addition, Figure 4 also indicates that heavy manufactures includes chemical, metal and machinery manufacturers keep a high percentage in location with lowest land price. While product wholesalers, retailers and light manufacturers include other manufacturers keep a high percentage in locations with higher land price. This can be interpreted that each individual enterprise will choose a location based on their industrial characteristics to maximize their profits.

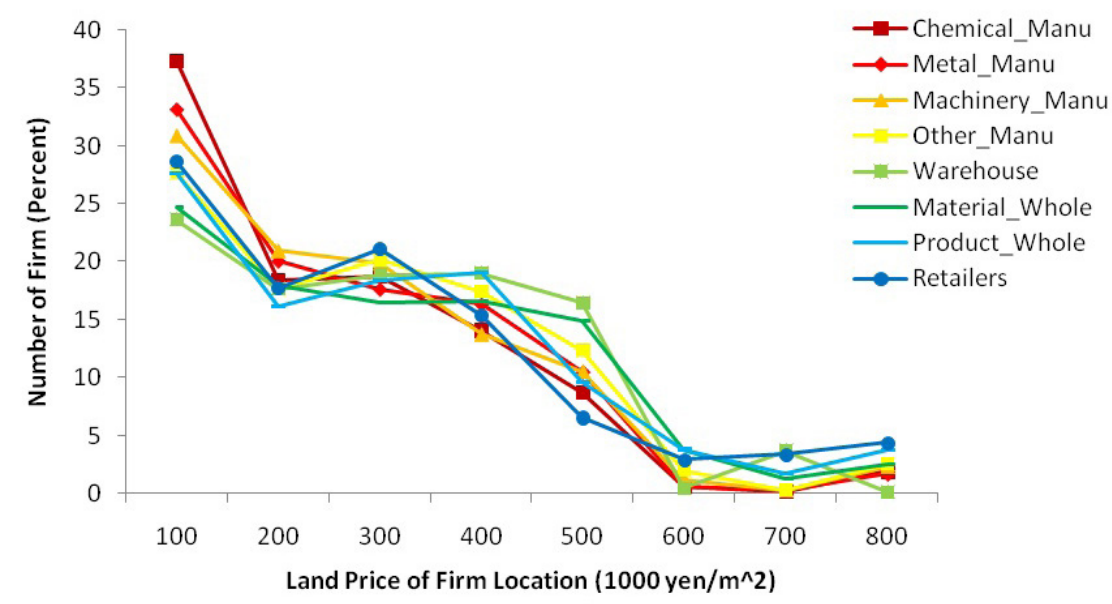

Figure 4. The enterprise distribution based on the land price of enterprise locations

The Figure 5 illustrates the individual enterprises distribution based on the travel distance to customers for all types of industry. More than 35 percentage of the retailers have travel distance within 5 $\mathrm{km}$ and the percent of the number of retailers decrease shapely when the travel distance increase. In addition, very few retailers have a travel distance around $65 \mathrm{~km}$ and tend to zero. In contrast, metal manufacturers, chemical manufacturers, machinery manufacturers and warehouses have a lower percentage of the number of enterprises within travel distance of $5 \mathrm{~km}$ and this percentage decrease slightly when the travel distance increase. This indicates that the commodity of retailers and wholesalers are distributed in the shorter travel distance than that of all types of manufacturers and warehouses. In which, the commodity of chemical manufacturers has the longest travel distance, and the commodity of retailers has the shortest travel distance to customers and suppliers. 


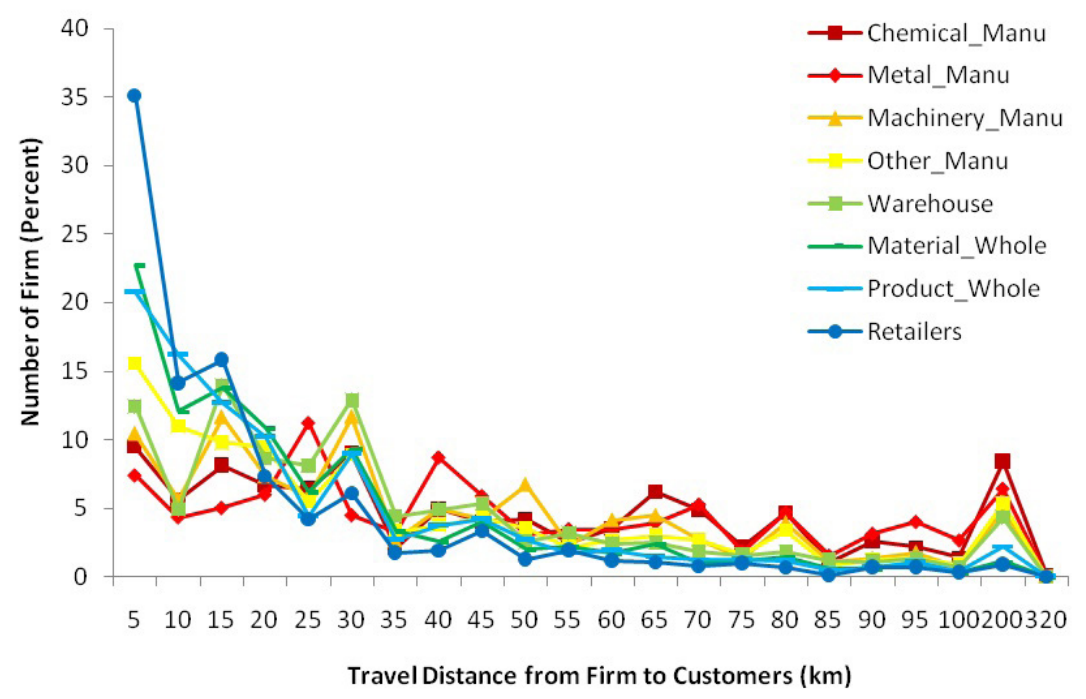

Figure 5. The enterprise distribution based on the travel distance to customers

The Figure 6 illustrates the enterprise distribution based on the total transportation cost of each enterprise. Transportation cost is assumed a function of travel distance and the weight of commodity for each enterprise. Transportation cost is calculated directly from the TMGM survey based on the weight of commodity $(\mathrm{kg})$ per day and the travel distance $(\mathrm{km})$ of each enterprise to customers and suppliers by each kind of vehicle. Transportation cost of each enterprise is the total transportation cost of all trips per day. Figure 6 shows that more than fifty percent of retailers, product wholesalers, material wholesalers and other manufacturers located in the location with lowest transportation cost. While, the transportation cost of chemical manufacturers, metal manufacturers, machinery manufacturers and warehouses are higher than that of retailers and wholesalers. However, the percentage of these manufacturers and warehouses reduces when the transportation cost increases. This means that the enterprises of all types of industry prefer the location with a low transportation cost to reduce the total cost of each enterprise. In fact, retailers, product wholesalers and material wholesalers often have a lower transportation cost than that of warehouses and all types of manufacturers. This can be interpreted that the commodity of retailers and wholesalers are distributed in shorter distances with smaller weight than that of warehouses and manufacturers. Transportation cost of each enterprise is one important factor which influences the maximum profit of an enterprise. Because transportation cost is one of the main costs for each enterprise. In addition, the results of Figure 6 indicates that most enterprises prefer to choose the location which has a low transportation cost. This means that transportation cost keeps an important role in the location decision making process of each enterprise. 


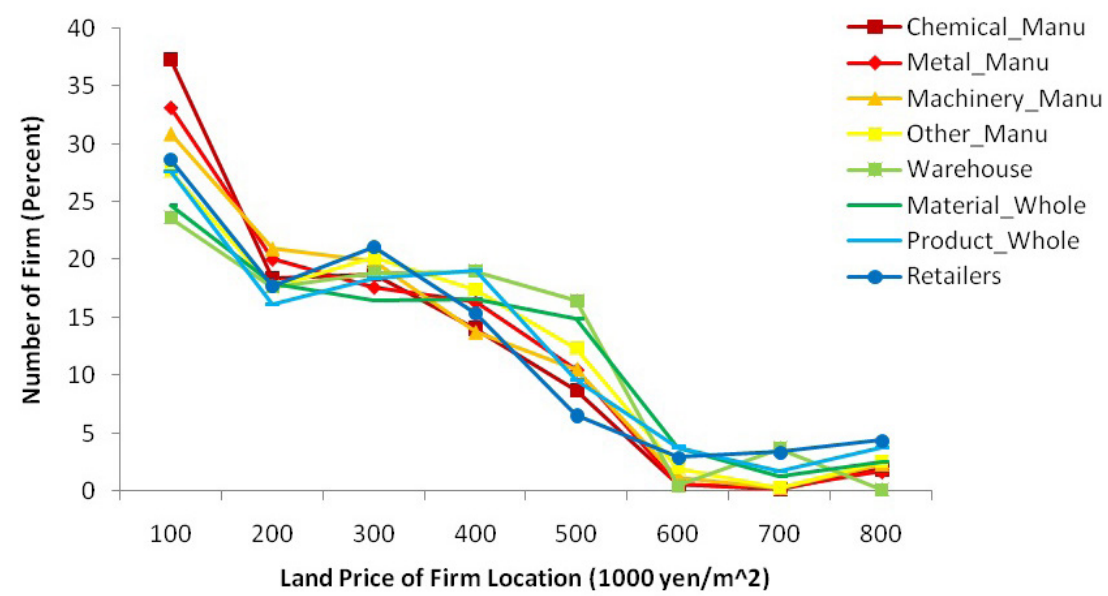

Figure 6. The enterprise distribution based on the total transportation cost

The Figure 7 illustrates the enterprise distribution based on the number of employees for each enterprise. In which, chemical manufacturers, metal manufacturers, machinery manufacturers have a higher average number of employees than that of material wholesalers, product wholesalers and retailers. This can be interpreted that these manufacturers often require much greater number of employees in their manufacturing. In addition, Figure 7 indicates that the percentage of number of retailers is highest for twenty people and this percentage reduces to almost zero for enterprises with 100 people. In contrast, all types of manufacturers have the lowest percentage of the number of enterprises with 20 people, but this percentage reduces slightly when the number of employee increases.

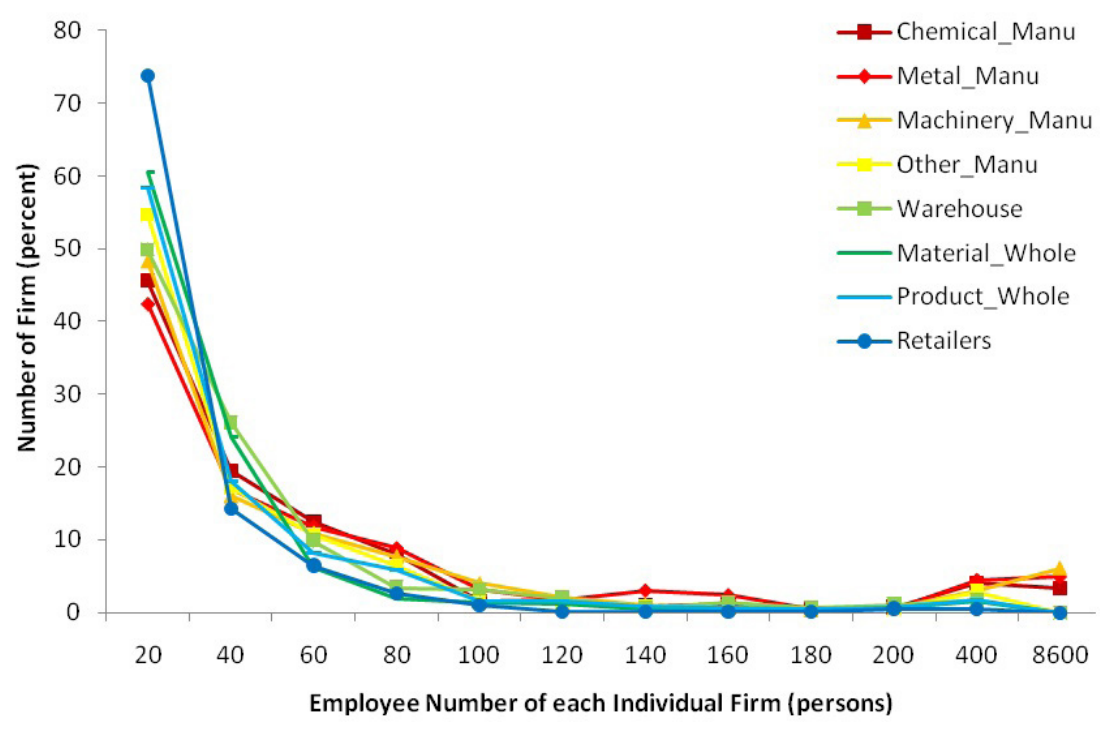

Figure 7. The enterprise distribution based on the number of employees

The Figure 8 depicts the distribution of enterprises based on the floor area. Retailers, material wholesalers and product wholesalers have a smaller average floor area than that of chemical manufacturers, metal manufacturers, machinery manufacturers and warehouses. Regarding with the enterprise's floor area around $200 \mathrm{~m}^{2}$, Retailers have the highest percentage and warehouses have the lower number percentage of enterprise numbers. However, the percentage of retailers, other manufacturers, material 
wholesalers and product wholesalers reduce sharply when the floor area increases. The percentages of retailers reduce almost to zero when the floor area reaches around $4,000 \mathrm{~m}^{2}$. In contrast, the percentage of all types of manufacturers and warehouses still continue to increase slightly to $30,000 \mathrm{~m}^{2}$ and reduce to zero when the floor area of each individual enterprise reaches around $430,700 \mathrm{~m}^{2}$.

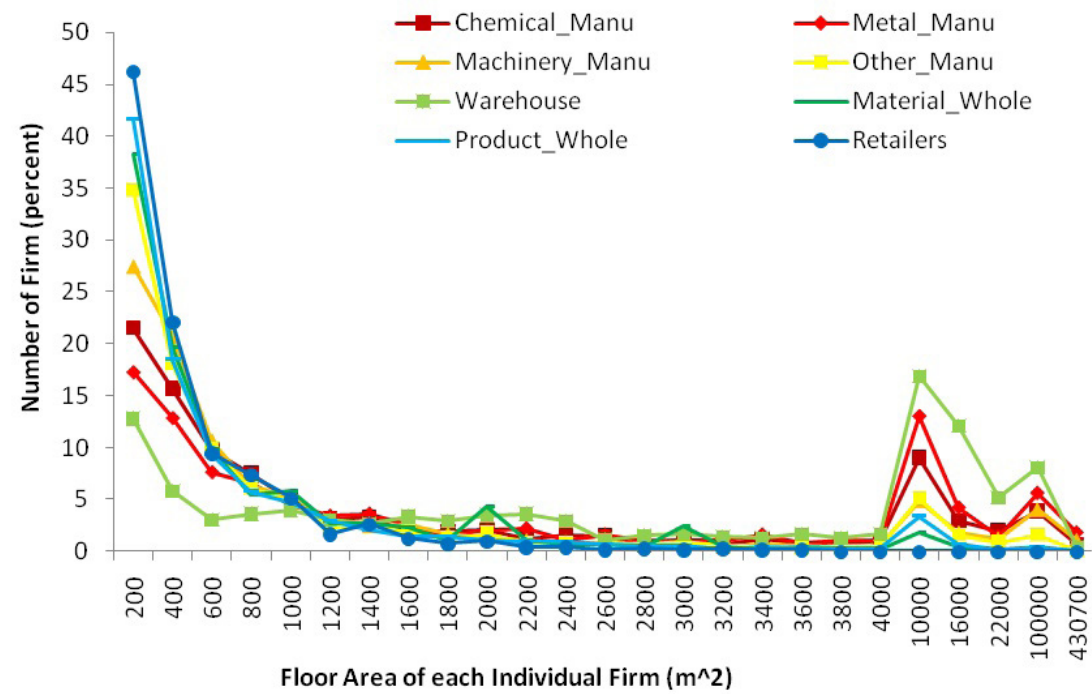

Figure 8. The enterprise distribution based on the number of employees

The Figure 9 shows the distribution of enterprise based on the total weight of commodity per day. In which, the commodity of retailers, material wholesalers and product wholesalers are distributed with smaller average weight than that of chemical manufacturers, metal manufacturer, machinery manufacturers and warehouses. The percentage of retailers reduces almost to zero when the weight of commodity reaches around 20 tons. In contrast, the percentages of all types of manufacturers and warehouses continue to increase slightly to 100 tons and reduce to zero at 9,900 tons.

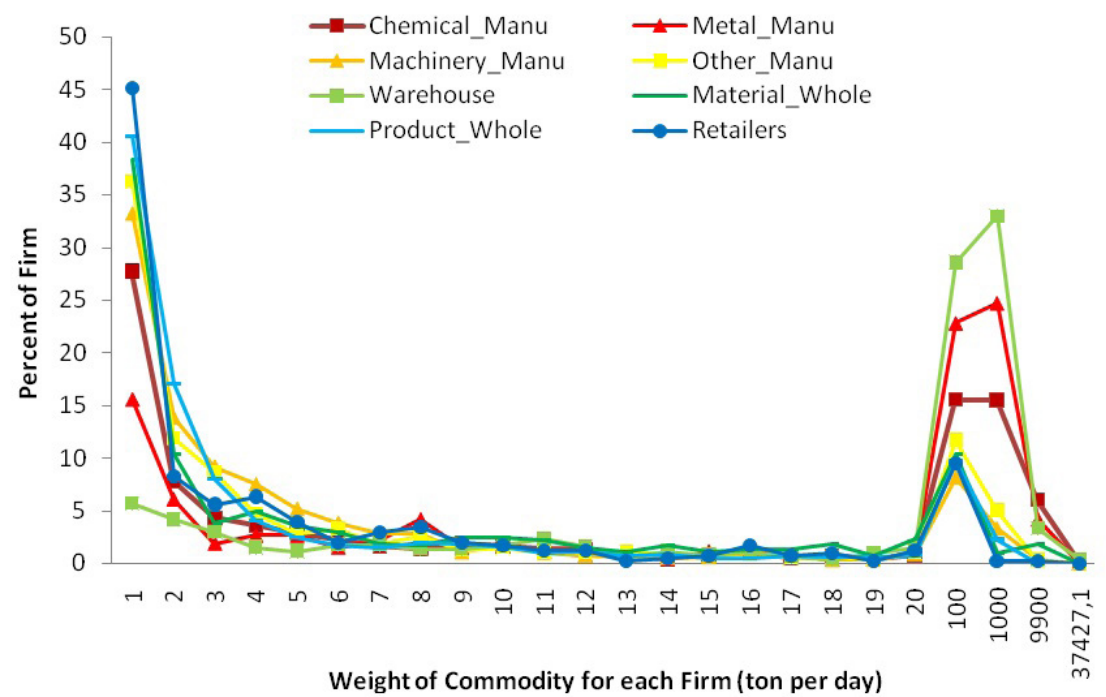

Figure 9. The enterprise distribution based on the total weight of commodity 


\section{$5 \quad$ Results and discussions}

This part will show the results of each kind of model and discussion of the influence of each factor on the location choice model of each enterprise. Especially, the influence of the urban spatial effects on the enterprise location choice decision will be discussed carefully to understand the urban spatial correlation among enterprises and urban spatial correlation among zones in the location choice decision behavior of each enterprise in a dynamic business environment. Moreover, the comparison among three models will be carried to clarify the important role of urban spatial effects in the proposed model. This comparison will be implemented on basis of three types of indicators such as the log likelihood ratio, Akaike information indicator and hit ratio of each model.

MNL model: Location choice model of an enterprise is estimated by the multinomial logit model without any kind of urban spatial effects.

MNLS model: Location choice model of an enterprise is estimated by multinomial logit model incorporating urban spatial effects in the deterministic part of the utility function. This model incorporates urban spatial effects to represent the urban spatial correlation among the enterprises in the enterprise location choice model.

MLS model: Location choice model of a company is estimated by mixed logit model incorporating urban spatial effects in both the deterministic part and the error part of the utility function. The proposed model incorporates urban spatial effects to represent both the urban spatial correlation among enterprises and the urban spatial correlation among zones in the enterprise location choice model.

The parameters of the three models are estimated and compared as well as the results are shown in Table 1 and Table 2. All of the three models give the same sign of parameters estimated, each of which is as expected. Based on these results, it is clear that the enterprise location choice model fit is improved as the model complexity increases; that is the MLS or the enterprise location choice model not only incorporating urban spatial effects among enterprises but also incorporating urban spatial effects among zones has the best performance over the other reference models for all types of industry including manufacturers, warehouses, wholesalers and retailers.

Table 1 and Table 2 show the estimation results' comparison among three models such as MNL, MNLS and MLS for each type of industry. In the empirical results, there is a difference in the number of variables among three models. Therefore, in terms of goodness of fit, the Akaike Information Criterion (AIC) should be considered in this study. The AIC test is utilized in order to penalize log-likelihood improvements due to a large number of parameters. In which, a higher value of the adjusted log-likelihood ratio is preferable, while a lower value of AIC is more desirable.

From Table 1 and Table 2, the MLS has the best performance and best model fit among three models. This means that urban spatial interactions among enterprises, zones keep an important role and greatly affect the enterprise location choice decision behavior. Besides, based on considering the results of the adjusted log-likelihood ratio, it is straightforward to see that the model performances of MNLS and MLS are better than that of the MNL, implying that the effects of urban spatial interactions among zones are not very strong comparing with the urban spatial interactions among enterprises in the enterprise location choice decision behavior. In other words, the location choice decision of these companies will be affected by the appearance of the other enterprises in the contiguous zones, the preference information from neighbor enterprises. The individual manufacturers prefer the industrial zone where there are many individual manufacturers located and especially the industrial zones which are near the current location of enterprises. This can be explained that the other manufacturers can receive benefits from the current infrastructure of industrial zones and the advantages of supply change systems between suppliers, customers, shippers and the existing enterprises, whereas the location choice decision of other manufacturers will be affected slightly by the boundary length of alternative zones with attractive zones or the contiguous alternative zones of industrial zones. 


\begin{tabular}{|c|c|c|c|c|c|c|c|c|c|c|c|c|c|c|}
\hline \multirow{3}{*}{ 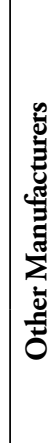 } & $\underset{z}{Z}$ & 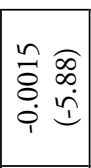 & 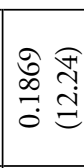 & 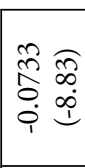 & 宅 & 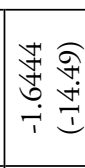 & 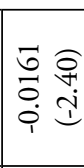 & 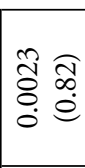 & 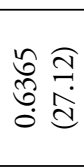 & 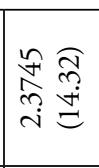 & 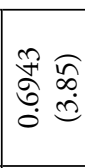 & 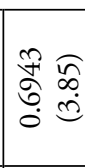 & 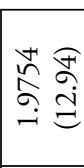 & 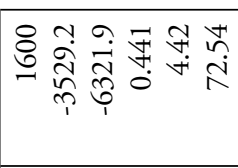 \\
\hline & $\mid \begin{array}{c}3 \\
3 \\
\vdots \\
z\end{array}$ & 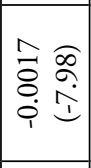 & 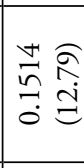 & \begin{tabular}{ll}
$\infty$ & 0 \\
\multirow{1}{*}{} & 0 \\
0 & 0 \\
0 & 0 \\
0 & 1
\end{tabular} & 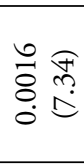 & 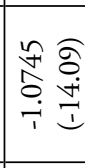 & $\begin{array}{ll}\tilde{\pi} & \widehat{\nwarrow} \\
\hat{0} & \hat{m} \\
0 & 1\end{array}$ & 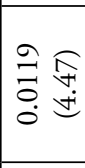 & 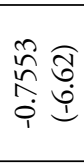 & 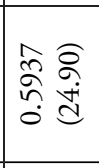 & 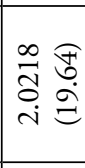 & ' & & 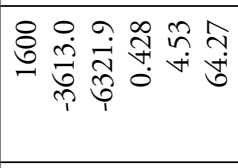 \\
\hline & $\underset{z}{\mathfrak{z}}$ & 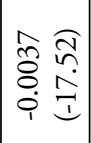 & 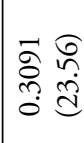 & 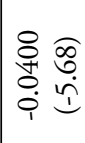 & 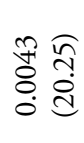 & 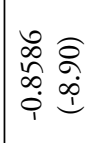 & 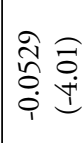 & 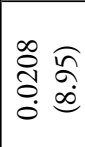 & 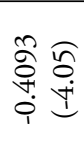 & & & 1 & & 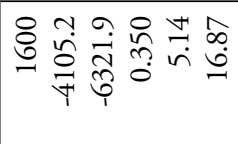 \\
\hline \multirow{3}{*}{ 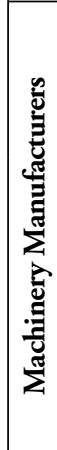 } & $\underset{3}{3}$ & 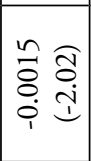 & $\begin{array}{ll}\vec{\delta} & \widehat{\sigma} \\
\stackrel{0}{0} & \stackrel{0}{0}\end{array}$ & 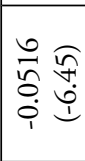 & 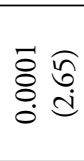 & 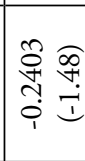 & 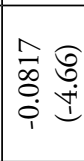 & $\begin{array}{l}\widehat{\widetilde{\sigma}} \widehat{\approx} \\
0 \\
0 \\
0\end{array}$ & 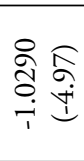 & 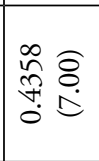 & 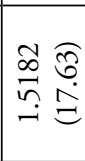 & 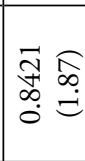 & 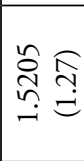 & 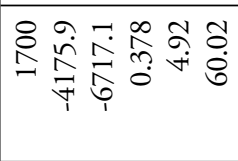 \\
\hline & $\underset{3}{3}$ & $\left|\begin{array}{cc}0 & \widehat{n} \\
0 & \stackrel{n}{i} \\
i & i\end{array}\right|$ & $\begin{array}{ll}0 & \widehat{n} \\
\tilde{\sigma} & \tilde{n} \\
0 & 0\end{array}$ & 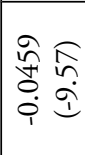 & 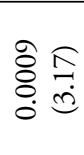 &  & 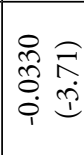 & $\begin{array}{l}\hat{\mathrm{O}} \\
\stackrel{\mathrm{T}}{\mathrm{T}} \\
\dot{0}\end{array}$ & 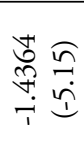 & 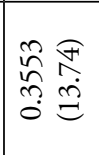 & 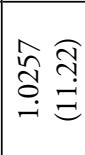 & ' & & 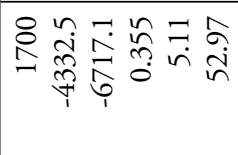 \\
\hline & $\underset{z}{Z}$ &  & 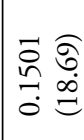 & 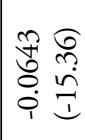 & 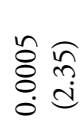 & 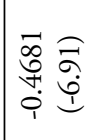 & 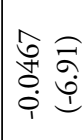 & $\mid \begin{array}{ll}0 & \widehat{a} \\
\vdots & 0 \\
0 & \pm \\
0 & \pm\end{array}$ & 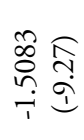 & & & ' & & 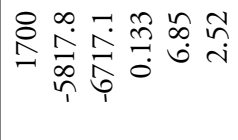 \\
\hline \multirow[t]{3}{*}{ 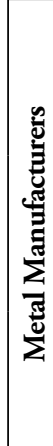 } & 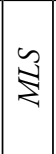 & $\left|\begin{array}{ll}0 & \widehat{\sigma} \\
0 & 0 \\
0 & i \\
i & 1\end{array}\right|$ & \begin{tabular}{l}
$\infty$ \\
\multirow{0}{0}{} \\
$\stackrel{0}{0}$ \\
0 \\
0
\end{tabular} & 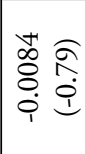 & 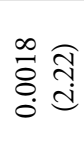 & 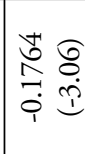 & 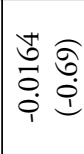 & $\begin{array}{l}\infty \\
0 \\
0 \\
0 \\
0 \\
0\end{array}$ & 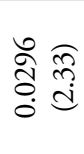 & 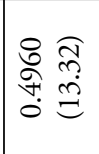 &  & 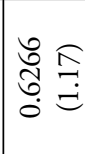 & 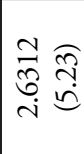 & 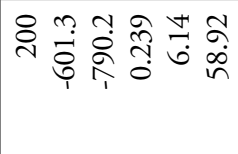 \\
\hline & $\underset{3}{3}$ & 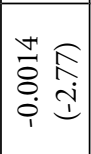 & 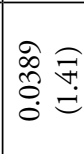 & $\begin{array}{ll}\infty & 0 \\
0 & 0 \\
0 & 0 \\
0 & 1\end{array}$ & $\begin{array}{l}\frac{n}{8} \widehat{n} \\
\stackrel{2}{a d} \\
0\end{array}$ & 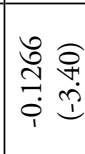 & 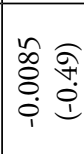 & 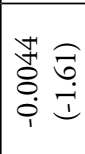 & 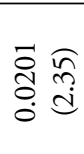 & 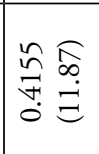 & 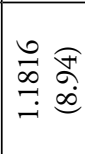 & ' & & 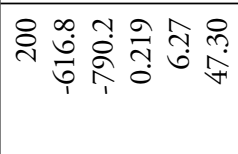 \\
\hline & 志 & 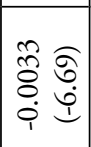 & \begin{tabular}{ll}
0 & 0 \\
\multirow{1}{1}{} & $\infty$ \\
0 & \pm \\
0 & \pm
\end{tabular} & 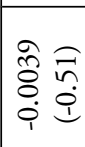 & 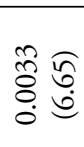 & 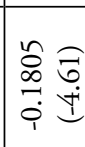 & 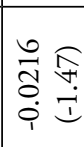 & 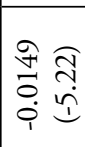 & 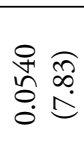 & & ' & ' & ( & 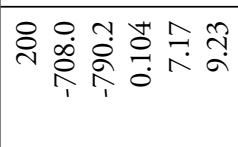 \\
\hline \multirow{3}{*}{ 递 } & $\begin{array}{l}3 \\
3 \\
z\end{array}$ & 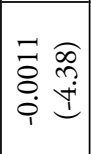 & 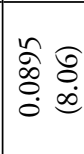 & 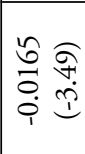 & 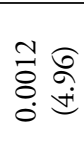 & 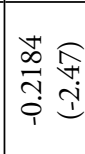 & 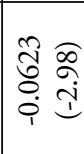 & 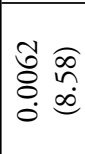 & 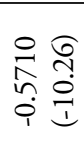 & 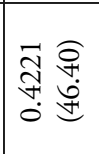 & 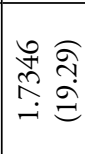 & 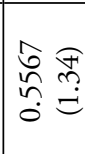 & 离 & 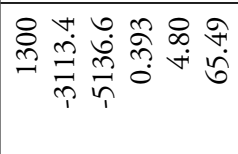 \\
\hline & $\underset{3}{3}$ & 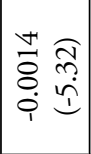 & 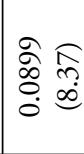 & $\mid \begin{array}{ll}\infty & 0 \\
\hat{0} & 0 \\
0 & i \\
0 & 1\end{array}$ & 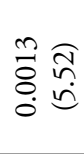 & 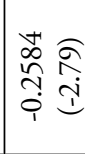 & $\begin{array}{ll}\overrightarrow{0} & \widehat{\sigma} \\
0 & \sigma \\
0 & \stackrel{1}{1}\end{array}$ & 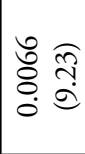 & 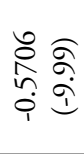 & $\mid \begin{array}{l}0 \\
\hat{n} \\
\hat{\tilde{n}} \\
0 \\
0\end{array}$ & 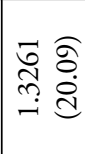 & ' & & 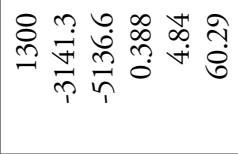 \\
\hline & 岁 & 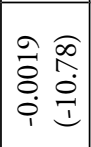 & $\begin{array}{ll}0 & 0 \\
\hat{N} & \stackrel{2}{0} \\
0 & =\end{array}$ & 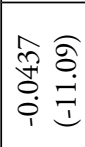 & 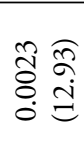 & 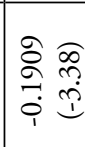 & 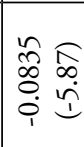 &  & 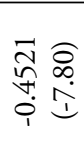 & & ' & ' & & 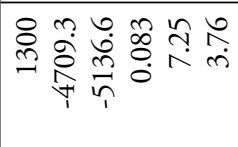 \\
\hline \multicolumn{2}{|c|}{ 尊 } & 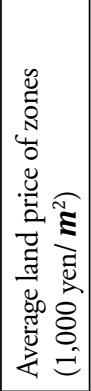 & 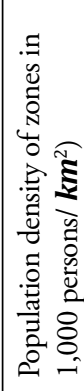 & 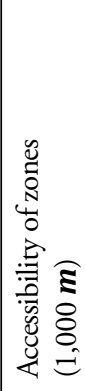 & 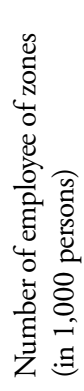 & 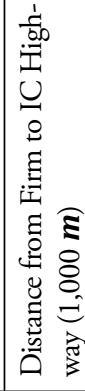 & 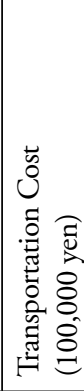 & 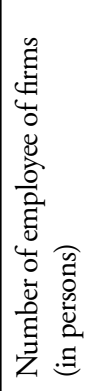 & 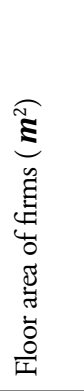 & $\infty$ & $\prec$ & $a$ & 0 & 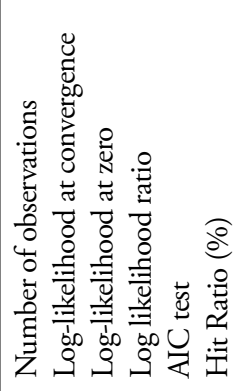 \\
\hline
\end{tabular}




\begin{tabular}{|c|c|c|c|c|c|c|c|c|c|c|c|c|c|}
\hline 3 & 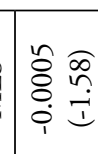 & 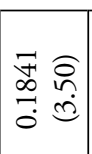 & 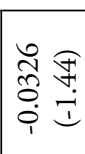 & 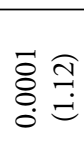 & 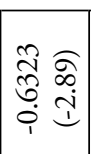 & 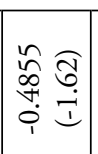 & \begin{tabular}{ll}
$\overrightarrow{\vec{\sigma}}$ & \multicolumn{1}{c}{} \\
0 & 0 \\
& 0
\end{tabular} & $\begin{array}{l}\sqrt{n} \hat{\wp} \\
\hat{\hat{o}} \\
\hat{\varrho}\end{array}$ & 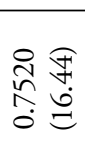 & 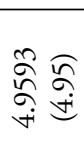 & 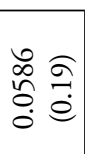 & 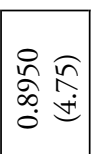 & 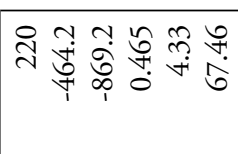 \\
\hline \multirow[t]{2}{*}{ 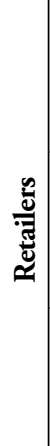 } & 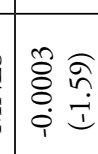 & 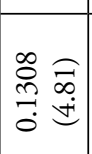 & 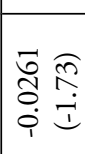 & $\begin{array}{l}\overrightarrow{8} \\
\stackrel{0}{0} \\
0 \\
0\end{array}$ & 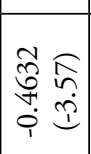 & 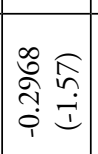 & 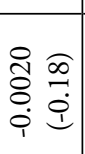 & 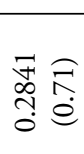 & 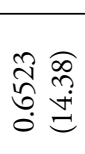 & 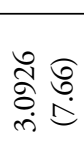 & . & & 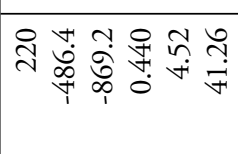 \\
\hline & 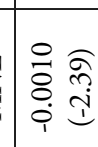 & 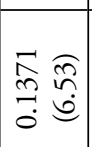 & 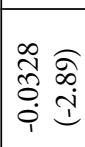 & $\begin{array}{l}0 \\
\varnothing \\
0 \\
0\end{array}$ & 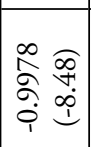 & 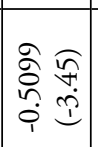 & 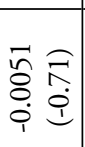 & $\begin{array}{l}\text { No } \\
\hat{\sigma} \\
\stackrel{0}{0} \\
0\end{array}$ & ' & & ' & & 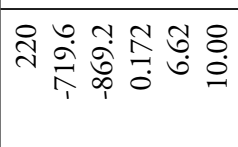 \\
\hline$\underset{z}{z}$ & 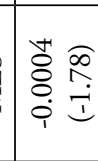 & $\left|\begin{array}{cc}\tilde{N} & \tilde{\sigma} \\
0 & 0 \\
0 & \dot{d}\end{array}\right|$ & 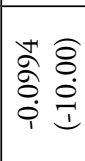 & 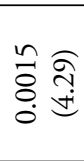 & 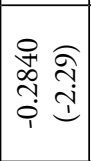 & 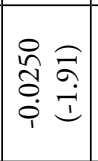 & 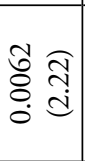 & 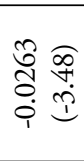 & 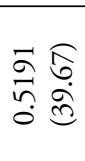 & 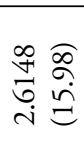 & 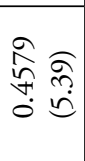 & $\left|\begin{array}{ll}\widehat{\hat{\sigma}} & \widehat{\sigma} \\
\hat{\sigma} & 0 \\
-i & 0\end{array}\right|$ & 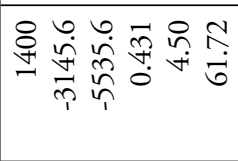 \\
\hline 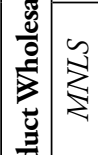 & $\begin{array}{l}m \\
\overrightarrow{8} \\
0 \\
i \\
i \\
i\end{array}$ & 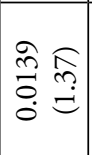 & 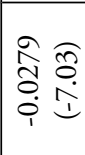 & 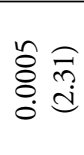 & 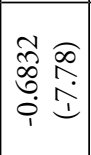 & 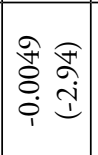 & $\begin{array}{l}\infty \\
\infty \\
\stackrel{\sqrt[f]{f}}{0} \\
\dot{0}\end{array}$ &  & 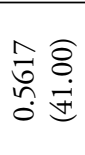 & 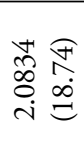 & ' & & 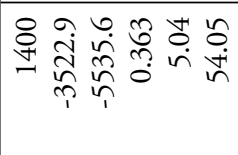 \\
\hline 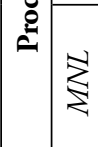 & 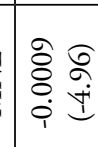 & 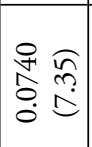 & 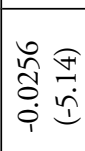 & $\begin{array}{l}\text { तै } \\
\stackrel{0}{0} \\
0 \\
0 \\
0\end{array}$ & 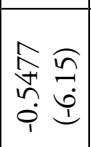 & 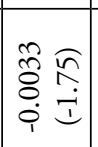 & 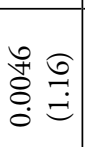 & $\begin{array}{l}\infty \\
0 \\
0 \\
0 \\
0 \\
i \\
i\end{array}$ & ' & & ' & & 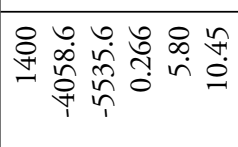 \\
\hline \multirow{3}{*}{ 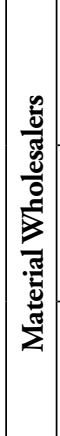 } & 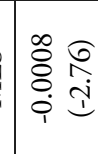 & 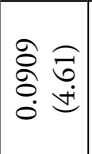 & $\mid \begin{array}{ll}\text { तิ } & \widehat{\alpha} \\
0 & 0 \\
0 & 0 \\
i & 1\end{array}$ & $\begin{array}{l}\vec{\sigma} \widehat{\Im} \\
\stackrel{d}{d} \\
\dot{d}\end{array}$ & 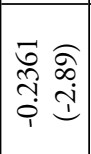 & 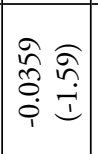 & 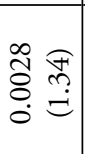 & 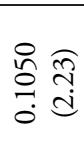 & 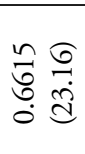 & 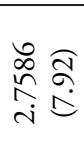 & $\begin{array}{l}\vec{F} \\
\stackrel{f}{f} \\
\stackrel{0}{0}\end{array}$ & 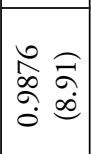 & 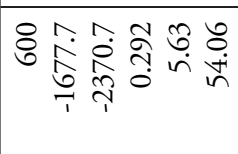 \\
\hline & $\begin{array}{l}0 \\
0 \\
0 \\
i \\
i\end{array}$ & 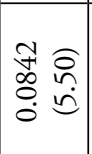 & 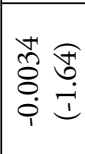 & $\begin{array}{l}\circ \\
\stackrel{0}{0} \\
0 \\
0 \\
0\end{array}$ & 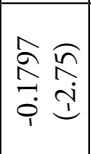 & 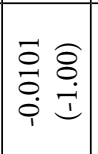 & $\begin{array}{l}\stackrel{n}{0} \\
\stackrel{0}{0} \\
\stackrel{0}{0}\end{array}$ & $\begin{array}{l}\text { Ô. } \\
0 \\
0 \\
0 \\
0\end{array}$ & $\begin{array}{l}\infty \\
\hat{\hat{\sigma}} \\
\hat{\tilde{o}} \\
\hat{0}\end{array}$ & 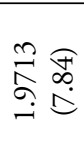 & ' & & 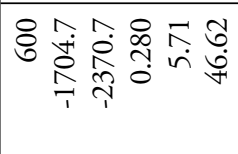 \\
\hline & 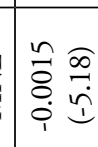 & $\left|\begin{array}{cc}0 & 0 \\
\multirow{2}{*}{} & 0 \\
\hdashline & 0 \\
0 & \Xi \\
=\end{array}\right|$ & $\begin{array}{ll}0 & 0 \\
0 & 0 \\
0 & 0 \\
0 & i \\
& i\end{array}$ & 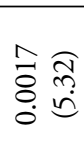 & 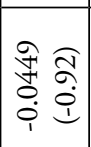 & 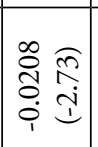 & 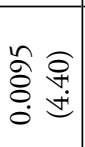 & $\begin{array}{l}\frac{N}{2} \\
\hat{n} \\
\stackrel{0}{0}\end{array}$ & ' & & ' & & 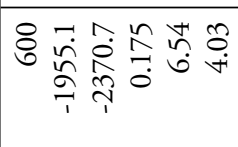 \\
\hline & 㑒 & $\left|\begin{array}{ll}\tilde{\sigma} & \widehat{\sigma} \\
\vdots & 0 \\
0 & \infty \\
0 & \infty\end{array}\right|$ & $\begin{array}{ll}\kappa & 0 \\
\hat{n} & 0 \\
0 & \tilde{p} \\
i & 1\end{array}$ & 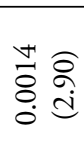 & 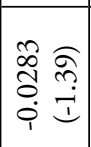 & 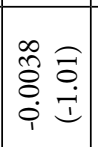 & 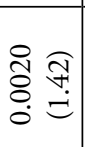 & 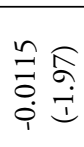 & 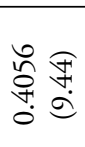 & 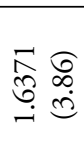 & 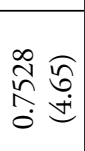 & 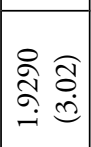 & 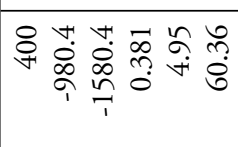 \\
\hline & 咅 & 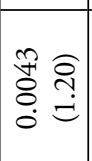 & 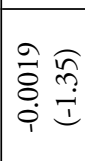 & 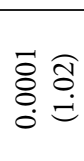 & 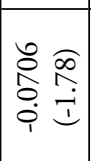 & 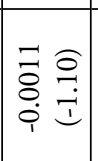 & 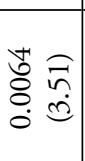 & 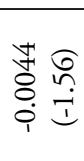 & 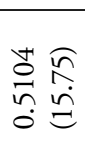 & 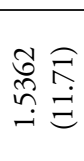 & ' & & 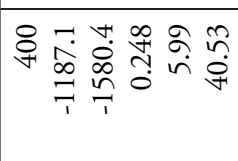 \\
\hline & 蒙 & 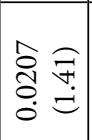 & 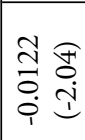 & $\begin{array}{l}n \\
\frac{n}{8} \\
0 \\
0\end{array}$ & $\left|\begin{array}{ll}0 & 0 \\
0 & 0 \\
0 & \ddots \\
0 & 1 \\
1 & 1\end{array}\right|$ & 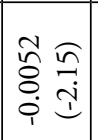 & 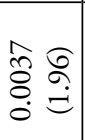 & 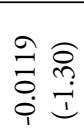 & ' & & ' & & 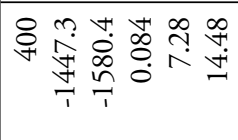 \\
\hline$\frac{3}{\frac{3}{0}}$ & 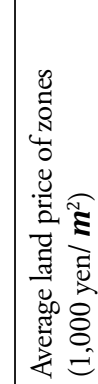 & 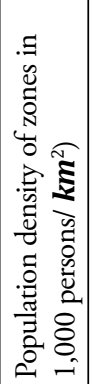 & 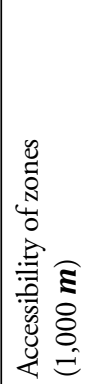 & 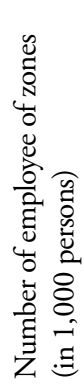 & 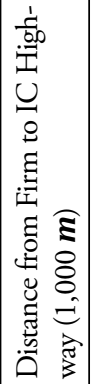 & 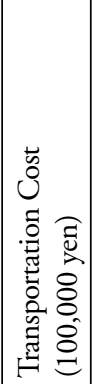 & 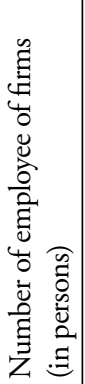 & 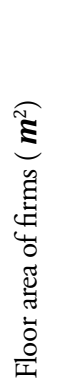 & $\infty$ & $<$ & $a$ & 0 & 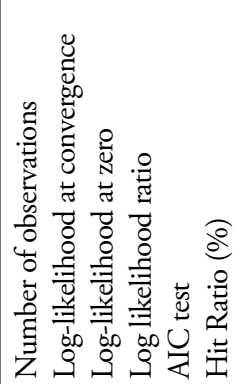 \\
\hline
\end{tabular}


In addition, these tables present a significant improvement in the model fit confirming the improvement of the explanatory power of the model as results of incorporating urban spatial interactions among enterprises and urban spatial interactions among zones. Furthermore, it is straightforward to say that the best model performance in terms of AIC test or Hit ratio is the MLS or the proposed model for chemical manufacturers, metal manufacturers, machinery manufacturers, other manufacturers, warehouse, material wholesalers, product wholesalers and retailers. This result confirms again the MLS is the best model performance for all types of industries. The results emphasize the fact that the urban spatial interactions among enterprises and among zones keep a significant role to improve the model performance of enterprise location choice decision. The reason for this is that the enterprise prefers the zones with the high aggregation of enterprises. In other words, it means that the enterprise likes to locate at attractive zones with a large market, suppliers and customers.

\section{The estimation results of the proposed model by MLS}

From the results, it is clear that the average land price coefficients have statistically significant and negative signs for enterprises which belong to all types of industries in this research. This means that the average land price has a significant negative effect on an enterprise's decision to select a particular location in the case of all manufacturers, warehouses, wholesalers and retailers. The reason for this is that enterprises like to locate in zones that have a lower land price in order to realize the maximum profit. In addition, the average land price variables are statistically significant for all enterprises in this model. Average land price factor, therefore, is an important factor that keeps a key role in the location choice decision of enterprises. The transportation cost coefficients have a statistically significant and negative signs for enterprises of all manufacturers, warehouses, wholesalers and retailers. The significantly negative signs of transportation cost parameters mean that transportation cost has a significant negative effect on enterprise location choice decision. In other words, most enterprises prefer location which is located near their customers, and their suppliers to reduce the transportation cost in order to realize their maximum profit purpose. Transportation cost factor, therefore, is an important factor which plays a key role in the location choice decision of many enterprises. The urban spatial correlation parameters are statistically significant in terms of the t-statistics with reasonable signs for all types of enterprises. This means that the role of urban spatial interactions and urban spatial correlation in the location choice decision behavior of enterprises in the Tokyo Metropolitan area. The values of the correlation coefficients indicate the effectiveness of the enterprise location choice model when it incorporates the urban spatial correlation among zones in the error term, and when it incorporates the urban spatial correlation among individual enterprises in the deterministic term of utility function. In addition, the influence level of urban spatial interactions among enterprises on the zone choice probability is higher than that of urban spatial interactions among zones. The t-statistic values of urban spatial parameters indicate that the parameters of the urban spatial interactions among enterprises are more important than that of urban spatial interactions among zones in the proposed location choice model.

Transportation cost parameter for retailers is the lowest since it is true that the distribution of commodities from retailers is in a short distance and the weight of commodities is less than that of manufacturers, warehouses and wholesalers. Moreover, the value of the transportation cost parameter for chemical manufacturers, metal manufacturers, machinery manufacturers, warehouses and other manufacturers are high, it can be interpreted that the weight of commodities of these manufacturers is large and the distribution of commodities from manufacturers to customers is generally distributed in the long distance. 
The urban spatial dependency factor is a generic variable with positive signs for both parameters $\lambda$ and $\boldsymbol{\delta}$ in all alternatives. It generated the expected signs and magnitudes of parameters. The positive sign of $\boldsymbol{\lambda}$ in the model indicates that the increasing of travel distance among enterprises is directly associated with the choice of development type. High significant t-statistics for these two parameters suggest that neighbor enterprise's effects are very important in the model developed in this study.

Figure 10 indicates that the urban spatial interaction reaches the highest value when there is only one adjacent zone. This can be interpreted that when the zone located contiguously with only other zone which has a good attractiveness. This zone may get the much more benefit from the good attractive zone. The urban spatial interactions among zones tend to reduce when the number of adjacent zones increases. It can be interpreted that the level of urban spatial interactions may be separated corresponding with each adjacent zone which has a different attractiveness.



Figure 10. Number of adjacent zones and urban spatial effects

From Figure 10, it is straightforward to see that the influence level of urban spatial interactions among zones on the location choice decision of the manufacturers is higher than that of theses urban spatial effects for retailers, material wholesalers and product wholesalers. This means that the location choice decision of manufacturers which include chemical manufacturers, metal manufacturers, machinery manufacturers and other manufacturers will be affected by enterprises which located in the contiguous zones. This influence will be less important in the location choice decision for retailers, material wholesalers and product wholesalers. It can be interpreted that commodities between manufacturers and customers, suppliers are normally distributed in longer distance than the radius of each zone, while this travel distance is shorter than the radius of each zone for retailers and material wholesalers.

\section{$6 \quad$ Conclusions and recommendations}

First, this paper has proposed an approach for the enterprise location choice model in an urban area. The urban spatial interactions considered in the proposed model make it more realistic in the actual situations. In which, the first proposed model takes into account the urban spatial interactions in the deterministic part of the utility function by using the multinomial logit model to represent the urban spatial correlation among enterprises. Additionally, the second proposed model not only takes into ac- 
count the urban spatial interaction in the deterministic part but also incorporates the urban spatial interactions in the error part by using mixed logit model to represent the urban spatial correlation among zone alternatives.

Second, this study has highlighted the influence of urban spatial effects on the enterprises decision behavior for location choice. A mixed logit model is applied, and the results indicate that the location choice decision of enterprises depends on the number of employees in a particular enterprise, transportation cost of each enterprise and the attributes of the zone such as the size of the population and the number of employees in the zone. Moreover, the results suggest that enterprises prefer to locate in zones that have a higher population density and a higher number of employees. Furthermore, the result clarifies the factors that play a key role in the decisions made by companies in selecting a location. Our findings confirm the important role of structuralized urban spatial effects and zone attributes in the decision-making process of enterprises.

Finally, this research has applied the proposed models to the Tokyo metropolitan area in the case study. The paper compared three modeling types: without any urban spatial interactions (MNL), with interactions among individual enterprises (MNLS) and with both interactions among individual enterprises and among zone alternatives (MLS). In addition, this study has estimated the performance of each model based on the log-likelihood ratio, AIC test and hit ratio values. The comparison results reveal that the best model performance is the MLS or the proposed model for all types of industries. Furthermore, the proposed model's results indicate that the urban spatial interactions significantly affect the location choice decision making behavior of each enterprise. In particular, the interaction with enterprises has a greater influence on an enterprise location choice decision than the interaction among zone alternatives.

The results of this study can be better in future studies on firm location choice models with considering the location factors that are measured at firm level. The obtained results still leave ample room for improvement because the present study is limited to a small data set for the estimation. It is expected that a better model performance will be achieved with an improved, larger set of data and the correlation between the corresponding attributes should be checked more carefully in the large set of data source. 


\section{References}

Ben-Akiva, M., Bolduc, D., \& Walker, J. (2001). Specification, identifications, and estimation of the logit kernel (or continuous mixed logit) model (PDF draft). Berkeley, CA: University of California Berkeley.

Bhat, C. R., \& Guo, J. A. (2004). Mixed spatially correlated logit model: Formulation and application to residential choice modeling, Transportation Research Part B, 38, 147-168.

Boots, B. N., \& Kanaroglou, P. S. (1988). Incorporating the effect of spatial structure in discrete choices models of migration. Journal of Regional Science, 28, 495-507.

de Bok, M., \& Sanders, F. (2005). Firm location and the accessibility of locations: Empirical results from the Netherlands. Transportation Research Record: Journal fo the Transportation Research Board, 1902(1), 35-43. https://doi.org/10.1177/0361198105190200105

de Bok, M. D., \& van Oort, F. (2011). Agglomeration economies, accessibility, and the spatial choice behavior of relocating firms. Journal of Transport and Land Use, 4, 5-24.

Dubin, R. A. (1995). Estimating logit models with spatial dependence. In L. Anselin \& R. Florax (Eds), New directions in spatial econometrics (pp. 229-242). Heidelberg: Springer-Verlag.

Fotheringham, A. S. (1983). A new set of spatial-interaction models: The theory of competing destinations. Environment and Planning A, 15(1), 15-36. https//: doi.10.1068/a150015

Griffith, D. A. (1996). Some guidelines for specifying the geographic weights matrix contained in spatial statistical models (Chapter 4). In A. L. Arlinghaus, D. A. Griffith, W. C. Arlinghaus, W. D. Drake, \& J. D. Nystuen (Eds.), Practical handbook of spatial statistics. Boca Raton, FL: CRC Press.

Löchl, M., \& Axhausen, K. W. (2010). Modelling hedonic residential rents for land use and transport simulation while considering spatial effects. Journal of Transport and Land Use, 3(2), 39-63.

Maoh, H., \& Kanaroglou, P. (2007). Business establishment mobility behavior in urban areas: A microanalytical model for the city of Hamilton in Ontario, Canada. Journal of Geographic Systems, 9, 229-252.

McMillen, D. P. (1992). Probit with spatial autocorrelation. Journal of Regional Science, 32(3), 335-348.

McQuaid, R. W., Greig, M., Smyth, A., \& Cooper, J. (2004). The importance of transport in business' location decisions. (Reference no. UG494 ). Report to Department for Transport, Napier University, Edinburg, UK.

Miaou, S., \& Sui, D. (2004). Implications of changing demographic and socioeconomic structures on highway safety: A Texas initiative. Final report. Austin: Texas Transportation Institute.

Miyamoto, K., Vichiensan, V., Shimomura, N., \& Paez, A. (2004). Discrete choice model with structuralized spatial effects for location analysis. Transportation Research Record: Journal of the Transportation Research Board, 1898, 183-190. Washington, DC: Transportation Research Board of the National Academies.

Mohammadian, A., \& Kanaroglou, P. S. (2003). Application of spatial multinomial logit model to transportation planning. Paper presented at the 10th International Conference on Travel Behavior Research, Lucerne.

Mohammadian, A., Haider, M., \& Kanaroglou, P. S. (2005). Incorporating spatial dependencies in random parameter discrete choice models. Proceedings of the 84th Annual Transportation Research Board (CD-ROM). Washington, DC: Transportation Research Board.

Nilsen, O. L., Tørset, T., Gutiérrez, M. D., Cherchi, E., \& Andersen, S. N. (2020). Where and why do firms choose to move? Empirical evidence from Norway. Journal of Transport and Land Use, 13(1), 207-225. https://doi.org/10.5198/jtlu.2020.1424

Ozmen-Ertekin, D., Ozbay, K., \& Holguín-Veras, J. (2007). Role of transportation accessibility in attracting businesses to New Jersey. Journal of Urban Planning and Development, 133(2), 138-149. 
Paez, A., \& Suzuki, J. (2001). Transportation impacts on land use changes: An assessment considering neighborhood effect. Journal of Eastern Asia Society for Transportation Studies, 4, 47-59.

Pellegrini, P. A., \& Fotheringham, A. S. (2002). Modelling spatial choice: A review and synthesis in a migration context. Progress in Human Geography, 26(4), 487-510.

Pellenbarg, P. H., van Wissen, L. J. G, \& Van Dijk, J. (2002). Firm migration. In P. McCann (Ed.), Industrial location economics (pp. 110-148). Cheltenham: Edward Elgar Publishing.

Schirmer, P. M., van Eggermond, M. A., \& Axhausen, K. W. (2014). The role of location in residential location choice models: A review of literature. Journal of Transport and Land Use, 7(2), 3-21. https:// doi.org/10.5198/jtlu.v7i2.740

Train, K. E. (2003). Discrete choice methods with simulation. New York: Cambridge University Press.

Van Dijk, J., \& Pellenbarg, P. H. (2017). Firm migration. In International encyclopedia of geography: People, the earth, environment and technology. Hoboken, NJ: John Wiley \& Sons. https://doi. org/10.1002/9781118786352.wbieg0814

Wisetjindawat, W., Sano, K., \& Matsumoto, S. (2006). Commodity distribution model incorporating spatial interactions for urban freight movement. Transportation Research Record: Journal of the Transportation Research Board, 1966, 41-50. 